\title{
Chest CT Profile of Non-COVID Pediatric Patients During the Pandemic
}

\author{
Pritviraj SK $^{1} \cdot$ Rupali Jain ${ }^{1} \cdot$ Manisha Jana ${ }^{1}$ (D) $\cdot$ Ashu Seith Bhalla ${ }^{1} \cdot$ Priyanka Naranje $^{1} \cdot$ Arun K. Gupta $^{1}$
}

Received: 6 April 2021 / Accepted: 3 May 2021 / Published online: 26 May 2021

(C) Dr. K C Chaudhuri Foundation 2021

To the Editor: The ongoing COVID-19 pandemic, coupled with the lockdown in the April-June 2020 in India, resulted in a sharp fall in the patient attendance in the hospitals across the country [1]. We undertook a retrospective study to analyze the impact of COVID on pediatric chest CT referrals. The clinical indications for referral of all children $(<18 \mathrm{y})$, who underwent a chest CT between 1st April 2020 and 31st July 2020, were analyzed. COVID cases, CT showing COVID-like findings and trauma were excluded. For control, all pediatric chest CT during April-July (pre-pandemic) 2019 were included; excluding trauma. In both groups, clinical profiles were accessed through hospital information system. The clinical diagnoses were categorized as infective, neoplastic, and miscellaneous.

Total number of pediatric CT scans done during the study period were 198; out of which, chest CT scans of 'nonCOVID' and 'non-trauma' etiology were 54 (28 male, 26 female) in 2020 (group A); and 340 over a similar period in 2019 (group B). Children under 5 y of age constituted a larger proportion in group $\mathrm{A}$.

In group A, commonest cause for referral was malignancy $(24,44.4 \%)$. Other indications were suspected acute infection (29.6\%), acute exacerbation of chronic lung diseases (7.4\%), hemoptysis $(7.4 \%)$, and others (antenatally detected congenital malformations and pre-operative CT for elective surgeries).
Commonest malignancy was acute leukemia, followed by solid malignancies. Febrile neutropenia was the commonest indication of referral in malignancies $(9 / 54,16.7 \%)$. In comparison, in group $\mathrm{B}$, the number of patients with suspected/ diagnosed tuberculosis $(55 / 340,16.2 \%)$ and airway problems including asthma $(14 / 340,4.1 \%)$ were higher in proportion. Notable trend was the significant reduction in referral for tuberculosis and asthma during pandemic. This can be explained by a combined effect of the lockdown with less public interaction, and protective measures including wearing masks and limited vehicle movement leading to less air pollution.

\section{Declarations}

Conflict of Interest None.

\section{Reference}

1. McDonnell T, Nicholson E, Conlon C, et al. Assessing the impact of COVID-19 public health stages on paediatric emergency attendance. Int J Environ Res Pub Health. 2020;17:6719.

Publisher's Note Springer Nature remains neutral with regard to jurisdictional claims in published maps and institutional affiliations.

Manisha Jana

manishajana@gmail.com

1 Department of Radiodiagnosis, All India Institute of Medical Sciences, New Delhi 110029, India 